\title{
Phosphorous-containing nadicimide resins: synthesis and characterization
}

\author{
SARFARAZ ALAM, V G JAYAKUMARI, AMAR SINGH, \\ L D KANDPAL and I K VARMA* \\ Defence Materials and Stores Research and Development Establishment, DMSRDE P.O., \\ G.T. Road, Kanpur 208013, India \\ *Centre for Polymer Science and Engineering, Indian Institute of Technology, New Delhi \\ 110016, India
}

\begin{abstract}
A series of phosphorous-containing nadicimide end-capped resins, having different backbone, were prepared by reacting endo-5-norbornene- 2,3-dicarboxylic anhydride (nadic anhydride), pyromellitic dianhydride (PMDA)/3,3',4, 4'-benzophenone tetracarboxylic acid dianhydride (BTDA) and tris [3-azo(4-aminophenyl)] phosphine oxide (TAZP) in dimethyl acetamide. Yields were essentially quantitative. Structural characterization of resins was done by elemental analysis, IR and ${ }^{1} \mathrm{H}-\mathrm{NMR}$. Thermal behaviour of the resins was investigated by differential scanning calorimetry and thermogravimetric analysis, which revealed good high temperature performance. Isothermal ageing studies done at $340^{\circ} \mathrm{C}$ for various time periods showed good thermo-oxidative stability.
\end{abstract}

\section{Introduction}

Endo-5-norbornene-2,3-dicarboximide (nadicimide) end-capped imide resins are leading class of thermosetting polyimides which are being studied as matrix resins for advanced composites (Serafini et al 1972). The synergistic influence of phosphorous and nitrogen-containing functionalities, in improving the flame resistance of polymers, is well-documented in literature (Imai et al 1984; Mellisaris and Mikroyannidis 1989). Considerable work on such polymers has also been carried out in our laboratories (Sarfaraz Alam et al 1993 a, b, c, 1994 a, b, 1995 a, b).

In our continued effort to develop resins with better char yields the present investigations were undertaken. Resins with high char yields and high temperature capability are needed for ablative purposes. In this paper we report the synthesis of preformed nadicimide oligomers using tris [3-azo(4-aminophenyl)] phosphine oxide (TAZP). Incorporation of azo groups in preformed nadicimide may yield resins with better high temperature characteristics and solubility than the state-of-the-art resins.

Nine novel nadicimide end-capped resins, with azo linkages, have been synthesized by reacting nadic anhydride with tris [3-azo (4-aminophenyl)] phosphine oxide, and BTDA and PMDA were used for chain extension. TAZP was first reacted with nadic anhydride in various molar ratios to synthesize the oligomers $1-3.1$ and 2 were further chain extended by reactions with BTDA and PMDA in various molar ratios to obtain oligomers 4-9. The structure of the oligomers with sample designation and formulated molecular weight is shown in figure 1.

PZ-1 was also reacted with PMDA/BTDA (0.75 mole) to obtain oligomers PZ-1P and PZ-1B with FMW 3642 and 3746 respectively.

*Author for correspondence 


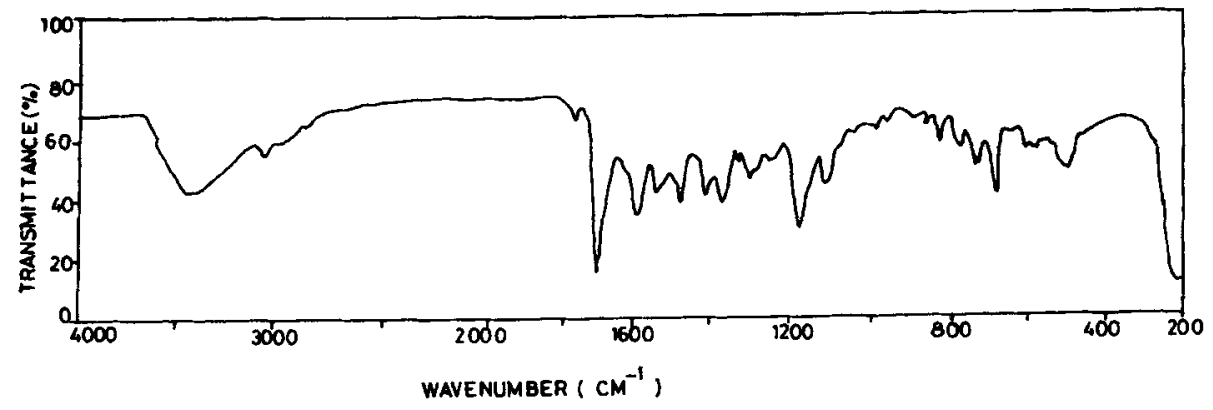

Figure 1. IR spectrum of PZ-1.

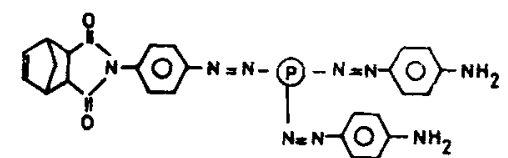

$$
\text { SAMPLE }
$$<smiles>CC(C)(C)N=Cc1ccc(N2C(=O)C3C4CCC(CC4)C3C2=O)cc1</smiles>

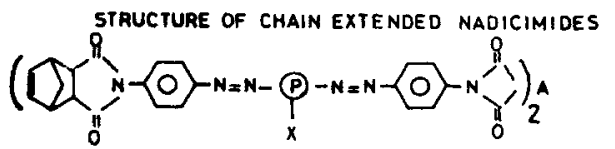

$$
\begin{aligned}
& \text { WHERE } X=-\mathrm{N}=\mathrm{N}-\mathrm{O}-\mathrm{NH}_{2}, A=0 \mathrm{O} \quad \mathrm{PZ}-0.5 \mathrm{P} \quad 1744 \\
& -\mathrm{N}=\mathrm{N}-\mathrm{O}-\mathrm{NH}_{2} \text { OO }
\end{aligned}
$$

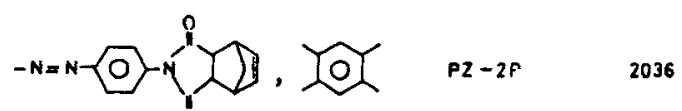

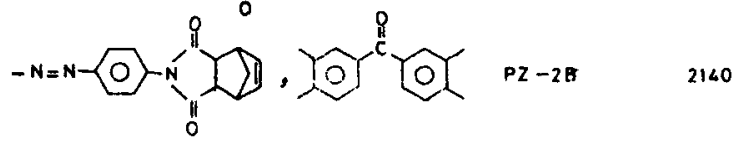

$$
\begin{aligned}
& P=\overbrace{0}^{-1}
\end{aligned}
$$

\section{Experimental}

$N, N$-dimethyl acetamide (DMAC) was kept over $\mathrm{P}_{2} \mathrm{O}_{5}$ for $12 \mathrm{~h}$ and distilled under reduced pressure. Nadic anhydride (Merck) was recrystallized from acetic anhydride $(\mathrm{BDH})$ and chloroform $(\mathrm{BDH})$ and dried under vacuum oven at $50^{\circ} \mathrm{C}$ for $12 \mathrm{~h}$. BTDA 
(Kochlight), PMDA (Fluka) were purified by recrystallization from acetic anhydride. TAZP was prepared from triphenyl phosphine oxide (Kochlight) by nitration and subsequent reduction according to the procedure reported earlier (Challenger and Wilkinson 1924), followed by diazotization and coupling with aniline (Merck) in acetone.

Nicolet MX-1 spectrophotometer was used for recording IR spectra. ${ }^{1} \mathrm{H}-\mathrm{NMR}$ spectra were recorded on a Jeol JNM-FX-100 FTNMR spectrophotometer. A Dupont 1090 thermal analyser, having a 951 TG module in combination with DSC cell, was used for thermal analysis. TG and DSC traces were recorded in air atmosphere at a heating rate of $10^{\circ} \mathrm{C} / \mathrm{min}$. Isothermal ageing was done at $340^{\circ} \mathrm{C}$ in air in muffle furnace.

\subsection{Synthesis of nadicimides}

Appropriate quantities of nadic anhydride and TAZP in DMAc $(20 \mathrm{ml})$ were refluxed for $12 \mathrm{~h}$ at $80^{\circ} \mathrm{C}$. The resulting amic acid was chemically cyclized by the addition of sodium acetate and acetic anhydride as cyclodehydrating agent. This reaction was carried out for $4 \mathrm{~h}$. The imides were precipitated in water, washed several times with water and aqueous sodium bicarbonate and dried under vacuum.

\subsection{Chain extension with dianhydrides}

The amino end-capped mono and bis-nadicimides were refluxed in DMAc with PMDA/BTDA for $10 \mathrm{~h}$ at $110^{\circ} \mathrm{C}$. The resulting amic acid was chemically cyclized by the addition of sodium acetate and acetic anhydride as cyclodehydrating agent. This reaction was carried out for $4 \mathrm{~h}$. The imides were precipitated in water, washed several times with water and aqueous sodium bicarbonate and dried under vacuum.

\section{Results and discussion}

The nadicimide oligomers were obtained in brown powder form with yield ranging from $60-83 \%$. Some of the physical characteristics of the oligomers are shown in table 1 .

Table 1. Physical characteristics of nadicimides.

\begin{tabular}{|c|c|c|c|c|c|c|c|}
\hline \multirow[b]{2}{*}{ No. } & \multirow{2}{*}{$\begin{array}{l}\text { Sample } \\
\text { designation }\end{array}$} & \multirow{2}{*}{$\begin{array}{l}\text { Yield } \\
(\%)\end{array}$} & \multicolumn{5}{|c|}{ Solubility } \\
\hline & & & Acetone & $\mathrm{CHCl}_{3}$ & DMF & DMAc & DMSO \\
\hline 1 & PZ-1 & 83 & +- & ++ & ++ & ++ & ++ \\
\hline 2 & PZ-2 & 74 & +- & +- & ++ & ++ & ++ \\
\hline 3 & PZ-3 & 77 & +- & ++ & ++ & ++ & ++ \\
\hline 4 & $\mathrm{PZ}-0.5 \mathrm{P}$ & 61 & +- & +- & ++ & ++ & ++ \\
\hline 5 & PZ-0.5B & 60 & +- & +- & ++ & ++ & ++ \\
\hline 6 & PZ-1P & 64 & +- & +- & ++ & ++ & ++ \\
\hline 7 & PZ-1B & 72 & +- & +- & ++ & ++ & ++ \\
\hline 8 & PZ-2P & 81 & +- & +- & ++ & ++ & ++ \\
\hline 9 & PZ-2B & 64 & +- & +- & ++ & ++ & ++ \\
\hline
\end{tabular}

- , Insoluble; ++ , highly soluble; +- , partially soluble. 
Table 2. Results of elemental analysis of nadicimides.

\begin{tabular}{|c|c|c|c|c|}
\hline \multirow{2}{*}{$\begin{array}{l}\text { Sample } \\
\text { designation }\end{array}$} & \multirow[b]{2}{*}{ Formula } & \multicolumn{3}{|c|}{ Elemental analysis $(\%)$} \\
\hline & & $\mathrm{C}$ & $\mathbf{H}$ & $\mathbf{N}$ \\
\hline PZ-1 & $\mathrm{C}_{45} \mathrm{H}_{36} \mathrm{O}_{3} \mathrm{~N}_{9} \mathrm{P}$ & $\begin{array}{c}69 \cdot 01 \\
(69 \cdot 14)\end{array}$ & $\begin{array}{c}4 \cdot 52 \\
(4 \cdot 61)\end{array}$ & $\begin{array}{c}16 \cdot 09 \\
(16 \cdot 13)\end{array}$ \\
\hline PZ-2 & $\mathrm{C}_{54} \mathrm{H}_{42} \mathrm{O}_{5} \mathrm{~N}_{9} \mathrm{P}$ & $\begin{array}{c}69 \cdot 81 \\
(69 \cdot 90)\end{array}$ & $\begin{array}{c}4.49 \\
(4.53)\end{array}$ & $\begin{array}{c}13.54 \\
(13.59)\end{array}$ \\
\hline PZ-3 & $\mathrm{C}_{63} \mathrm{H}_{48} \mathrm{O}_{7} \mathrm{~N}_{9} \mathrm{P}$ & $\begin{array}{c}70 \cdot 29 \\
(70-45)\end{array}$ & $\begin{array}{c}4 \cdot 41 \\
(4 \cdot 47)\end{array}$ & $\begin{array}{r}11 \cdot 73 \\
(11 \cdot 74)\end{array}$ \\
\hline PZ-0.5 P & $\mathrm{C}_{100} \mathrm{H}_{70} \mathrm{O}_{10} \mathbf{N}_{18} \mathrm{P}_{2}$ & $\begin{array}{c}68 \cdot 79 \\
(68 \cdot 81)\end{array}$ & $\begin{array}{c}3.95 \\
(4.01)\end{array}$ & $\begin{array}{r}14 \cdot 35 \\
(14 \cdot 44)\end{array}$ \\
\hline PZ-0.5 B & $\mathrm{C}_{107} \mathrm{H}_{74} \mathrm{O}_{11} \mathbf{N}_{18} \mathbf{P}_{2}$ & $\begin{array}{c}69.45 \\
(69.48)\end{array}$ & $\begin{array}{c}3.95 \\
(4.00)\end{array}$ & $\begin{array}{r}13.60 \\
(13.63)\end{array}$ \\
\hline PZ-1P & $\mathrm{C}_{210} \mathrm{H}_{138} \mathrm{~N}_{34} \mathrm{O}_{24} \mathrm{P}_{4}$ & $\begin{array}{c}69 \cdot 09 \\
(69-19)\end{array}$ & $\begin{array}{c}3 \cdot 65 \\
(3 \cdot 79)\end{array}$ & $\begin{array}{c}13.02 \\
(13.07)\end{array}$ \\
\hline PZ-1B & $\mathrm{C}_{217} \mathrm{H}_{142} \mathrm{~N}_{34} \mathrm{O}_{25} \mathrm{P}_{4}$ & $\begin{array}{c}69.39 \\
(69.51)\end{array}$ & $\begin{array}{c}3.61 \\
(3.79)\end{array}$ & $\begin{array}{c}12 \cdot 69 \\
(12 \cdot 71)\end{array}$ \\
\hline PZ-2P & $\mathrm{C}_{118} \mathrm{H}_{82} \mathrm{O}_{14} \mathrm{~N}_{18} \mathrm{P}_{2}$ & $\begin{array}{c}69.49 \\
(69.55)\end{array}$ & $\begin{array}{c}4.02 \\
(4.03)\end{array}$ & $\begin{array}{r}12 \cdot 35 \\
(12 \cdot 38)\end{array}$ \\
\hline PZ-2B & $\mathrm{C}_{125} \mathrm{H}_{86} \mathrm{O}_{15} \mathrm{~N}_{18} \mathrm{P}_{2}$ & $\begin{array}{c}70-01 \\
(70-09)\end{array}$ & $\begin{array}{c}3.99 \\
(4.02)\end{array}$ & $\begin{array}{c}11 \cdot 62 \\
(11 \cdot 78)\end{array}$ \\
\hline
\end{tabular}

${ }^{\mathrm{a}}$ Figures in parenthesis indicate calculated values.

The results of elemental analysis of the nadicimides are shown in table 2.

In the IR spectra of nadicimides characteristic bands due to imide groups appeared at $1780 \pm 10$ and $1720 \pm 10 \mathrm{~cm}^{-1}$. The presence of $\mathrm{NH}_{2}$ groups in the mononadicimides was indicated by $\mathrm{NH}$ stretching at $3230 \mathrm{~cm}^{-1}$. The absorption band due to $\mathrm{P}-\mathrm{C}_{6} \mathrm{H}_{5}$ and $>\mathrm{P}=\mathrm{O}$ for nadicimides were observed at 1430 and $1185 \mathrm{~cm}^{-1}$ respectively. The absorption band due to $-\mathrm{N}=\mathrm{N}$ was observed at $1530 \pm 10 \mathrm{~cm}^{-1}$ (figure 1 ). In samples containing BTDA, a broad absorption band was observed at $1700 \mathrm{~cm}^{-1}$ with a shoulder at $1660 \mathrm{~cm}^{-1}$, which is due to carbonyl stretching of the benzophenone group.

In the ${ }^{1} \mathrm{H}-\mathrm{NMR}$ spectra of nadicimides, aromatic protons were observed as a multiplet in the regions $\delta=7 \cdot 0-8.3 \mathrm{ppm}$, olefinic protons as singlet at $\delta=6.2 \mathrm{ppm}$, the methylene protons at $\delta=1.63 \mathrm{ppm}$, while the remaining aliphatic protons were observed in the region $\delta=3.34 \mathrm{ppm}$. In nadicimides containing free $\mathrm{NH}_{2}$ groups, the NH protons were observed at $\delta=2.08 \mathrm{ppm}$. The ratio of total aromatic protons to olefinic protons was used for structural characterization of nadicimides (figure 2).

Thermal behaviour of these resins was investigated by differential scanning calorimetry and thermogravimetric analysis. The exothermic transition associated with curing was observed in all the samples in the temperature range of $210 \pm 20$ $350 \pm 20$ (figure 3 ). The exothermic peak temperature $\left(T_{\text {exo }}\right.$, determined by extrapolation) was in the range of $265-295^{\circ} \mathrm{C}$. Table 3 gives the curing behaviour of some of the nadicimide oligomers.

The resins thermally cured at $300^{\circ} \mathrm{C}$ for $1 \mathrm{~h}$ in air showed a weight loss of $8-12 \%$. Thermogravimetric analysis results for cured resins in air are shown in table 4 . The major decomposition was observed above $285^{\circ} \mathrm{C}$ in TG traces (figure 4). Azo-nadicimides having free amino groups (viz. PZ-1, PZ-2) have shown lower thermal performance as compared to those devoid of this group. The chain extended nadicimides have shown 


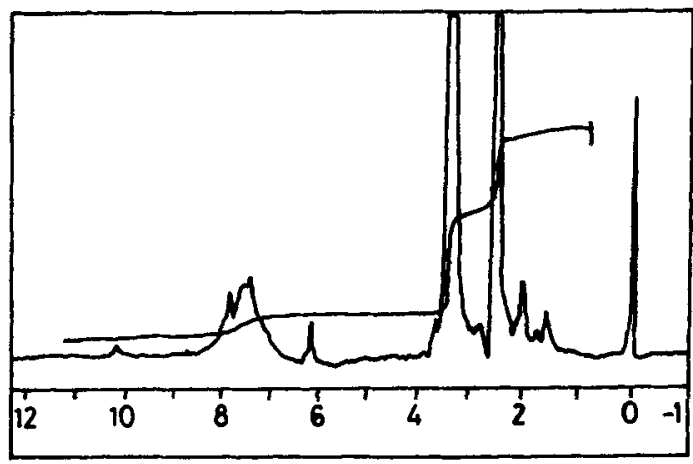

Figure 2. ${ }^{1} \mathrm{H}-\mathrm{NMR}$ spectrum of resin PZ-IP.

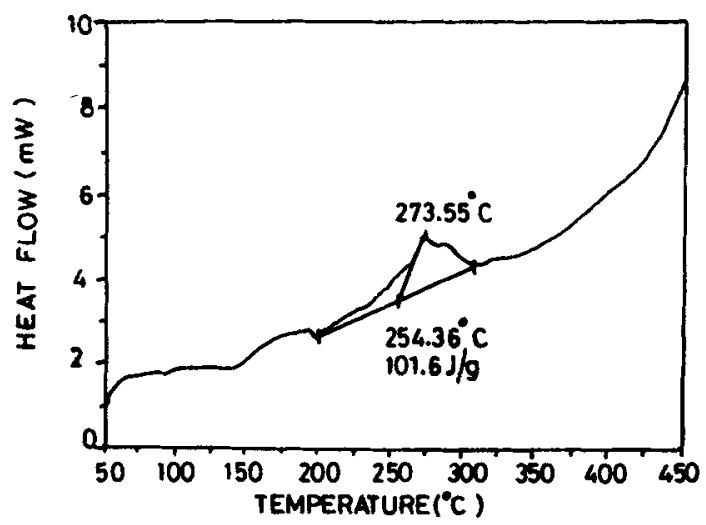

Figure 3. DSC scan of resin PZ-1.

Table 3. Curing behaviour of nadicimide resins.

\begin{tabular}{lcccc}
\hline $\begin{array}{l}\text { Sample } \\
\text { designation }\end{array}$ & $T_{\mathrm{i}}^{\mathrm{a}}$ & $T_{\mathrm{exo}}^{\mathrm{b}}$ & $T_{\mathrm{f}}^{\mathrm{c}}$ & $H(\mathrm{~J} / \mathrm{g})$ \\
\hline PZ-1 & $225 \cdot 2$ & $273 \cdot 5$ & $305 \cdot 0$ & $101 \cdot 6$ \\
PZ-2 & $235 \cdot 2$ & $285 \cdot 9$ & $306 \cdot 2$ & $95 \cdot 5$ \\
PZ-3 & $230 \cdot 5$ & $287 \cdot 1$ & $315 \cdot 2$ & $83 \cdot 2$ \\
PZ-1B & $234 \cdot 8$ & $298 \cdot 1$ & $360 \cdot 0$ & $108 \cdot 1$ \\
PZ-2P & $250 \cdot 1$ & $296 \cdot 4$ & $320 \cdot 0$ & $25 \cdot 8$ \\
& $325 \cdot 2$ & $352 \cdot 1$ & $400 \cdot 0$ & $12 \cdot 07$ \\
PZ-2B & $235 \cdot 8$ & $295 \cdot 0$ & $380 \cdot 0$ & $113 \cdot 0$ \\
\hline
\end{tabular}

${ }^{a}$ temperature of onset of exotherm; ${ }^{b}$ temperature of peak position; ${ }^{c}$ temperature of completion of exotherm.

high char yields as compared to lower analogues. The BTDA containing resins PZ-1B and PZ-2B have shown higher char yields as compared to PMDA incorporated nadicimides (PZ-1P, PZ-2P).

Thermo-oxidative stability of the oligomers were investigated by isothermal ageing at $340^{\circ} \mathrm{C}$. Percent weight loss in air after $150 \mathrm{~h}$ and $300 \mathrm{~h}$ are shown in table 4. 
Table 4. TGA data of cured nadicimide resins.

\begin{tabular}{|c|c|c|c|c|c|}
\hline \multirow{2}{*}{$\begin{array}{l}\text { Sample } \\
\text { designation }\end{array}$} & \multirow[b]{2}{*}{$T_{\mathrm{i}}^{\mathrm{a}}$} & \multirow[b]{2}{*}{$T_{1 / 2}^{\mathrm{b}}$} & \multirow{2}{*}{$\begin{array}{c}Y_{c}^{c} \\
(\%)\end{array}$} & \multicolumn{2}{|c|}{$\begin{array}{c}\% \text { wt. loss in } \\
\text { air at } 340^{\circ} \mathrm{C} \text { after }\end{array}$} \\
\hline & & & & $150 \mathrm{~h}$ & $300 \mathrm{~h}$ \\
\hline$P Z-1$ & $346 \cdot 1$ & $510 \cdot 1$ & 12 & $17 \cdot 7$ & $32 \cdot 7$ \\
\hline PZ-2 & 393.6 & 522.0 & 18 & $12 \cdot 8$ & $25 \cdot 4$ \\
\hline PZ-3 & $397 \cdot 3$ & 566.5 & 20 & $10 \cdot 1$ & 21.5 \\
\hline PZ-0.5 P & 361.0 & 675.8 & 35 & $22 \cdot 7$ & $30 \cdot 3$ \\
\hline PZ-0.5 B & $370 \cdot 0$ & 593.4 & 30 & $20 \cdot 7$ & 24.5 \\
\hline PZ-1P & $366 \cdot 2$ & $709 \cdot 8$ & 43 & 13.8 & $23 \cdot 1$ \\
\hline PZ-1B & $369 \cdot 9$ & $800 \cdot 0$ & 50 & $8 \cdot 2$ & $15 \cdot 4$ \\
\hline PZ-2P & $340 \cdot 0$ & 605.0 & 25 & $25 \cdot 2$ & 33.4 \\
\hline PZ-2B & 351.0 & $660 \cdot 0$ & 29 & $19 \cdot 0$ & $27 \cdot 1$ \\
\hline
\end{tabular}

Temperature of onset of decomposition; ${ }^{b}$ temperature at which $50 \%$ weight loss; char yield at $800^{\circ} \mathrm{C}$

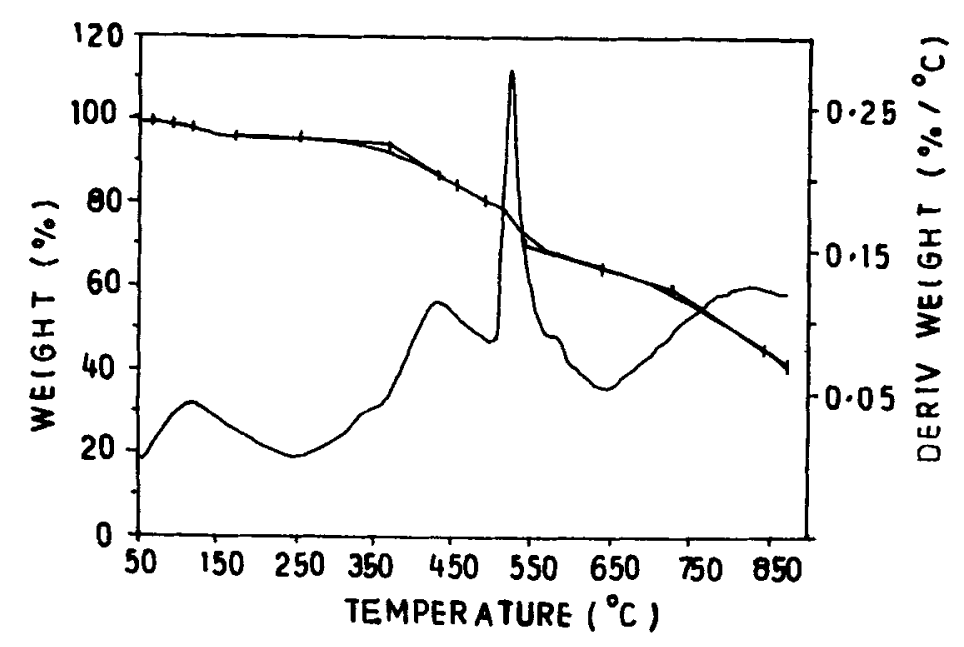

Figure 4. TG trace of resin PZ-1B (cured).

The results show good thermo-oxidative stability. Also, chain extended nadicimides containing BTDA exhibited lesser weight loss compared to PMDA incorporated nadicimides.

\section{Conclusions}

Performance of the nadicimide resins was studied based on two parameters, formula molecular weight and backbone structure of the resin. Phosphorous containing nadicimides with azo linkages had good solubility in common organic solvents. They exhibited good thermo-oxidative stability and good high temperature performance. 


\section{Acknowledgement}

The authors are thankful to Prof. G N Mathur, Director, DMSRDE, Kanpur for taking keen interest and providing continuous encouragement in this work.

\section{References}

Challenger F and Wilkinson J F 1924 J. Chem. Soc. 2675

Imai Y, Maldar N N and Kakimoto M 1984 J. Polym. Sci. Polym. Chem. 223771

Mellisaris A P and Mikroyannidis J A 1989 Eur. Polym. J. 25275

Sarfaraz Alam, Kandpal L D and Varma I K 1993a Tris (3-amino phenyl) phosphine oxide based methyl nadicimide resins, Proc. IX nat. symp. on thermal analysis, 25 pp 246-249

Sarfaraz Alam, Jayakumari V G, Kandpal L D and Varma I K 1993b Phosphorus containing nadicimide resins with amide linkages: synthesis and characterization, Proc. ISAMPE, pp 37-46

Sarfaraz Alam, Kandpal L D and Varma I K 1993c J. Macromol. Sci. C33 291

Sarfaraz Alam, Kandpal L D and Varma I K 1994a in Polymer sciences, Recent advances (ed.) I S Bhardwaj (Allied Publisher) Vol. I, pp 260-265

Sarfaraz Alam, Kandpal L D and Varma I K 1994b J. Appl. Polym. Sci. 531073

Sarfaraz Alam, Kandpal L D and Varma I K 1995a in Macromolecule, Current trends (ed.) S Venkatachalam (Allied Publisher) Vol. I, pp 365-372

Sarfaraz Alam, Kandpal L D and Varma I K 1995b in Macromolecule, Current trends (ed.) S Venkatachalam (Allied Publisher) Vol. II, pp 1035-1039

Serafini T T, Delvigs P and Lightsey G R, 1972 J. Appl. Polym. Sci. 161905 